\title{
Measuring Collaboration in Educational Wikis - A Methodological Discussion
}

\author{
doi:10.3991/ijet.v3i1.750 \\ Hagit Meishar-Tal and Edna Tal-Elhasid \\ Shoham Centre, The Open University of Raanana, Israel
}

\begin{abstract}
Measuring the collaboration in collaborative learning scenarios is important for assessment and research purposes. This paper describes the methodology developed in the Open University of Israel (OUI) to measure collaboration among students in wikis. It opens with an overview of the methods used to measure collaboration in Wikipedia, proceeds with explaining why these methods are not suitable enough for measuring collaboration in an educational wiki setting, and concludes by presenting a new method for measuring collaboration in educational wikis.
\end{abstract}

Index Terms-wikis; collaboration; collaborative learning; methodology.

\section{INTRODUCTION}

One of the goals of collaborative learning is to achieve genuine and productive collaboration among the participants [1], [2]. Therefore if learners do not collaborate during the learning process, not all the goals of the learning activity are achieved, and the process did not fully achieve its ends.

Measuring collaboration can indicate whether or not collaboration in fact occurred, and its intensity. It can also serve for assessment purposes. For example, if two groups are engaged in a collaborative learning activity, it can help the teacher decide which group is more collaborative and grade it accordingly.

Measurement of collaboration rates is also needed for research purposes. Investigating the influence of the teacher's feedback on the collaborative dynamics, or the influence of collaboration on the quality of the collaborative learning product, requires a measuring tool that can serve for comparison purposes.

The problem faced by many educators is how to measure the collaboration occurring during the collaborative learning process. This paper reveals the complexity involved in measuring collaboration in a specific collaborative environment, i.e. wikis, and describes the methodology developed by the Open University of Israel (OUI) to measure collaboration among students in educational wikis.

\section{MEASURING WIKIPEDIA}

Wikis are platforms for collaborative learning activities. They provide a facility to co-write documents from distance [3], [4], [5]. Wikis are also an effective platform for measuring collaboration. A complete history of editing on the Wiki pages is documented in the log file. Each edit is related to a specific user and to a specific page in the wiki [6]. This information can be very useful for assessment purposes in general and for measuring collaboration in particular. Nevertheless, the methodology needed for translating this information for assessment and research purposes is different in educational Wikis from in other Wikis. In the following paragraphs we will discuss the methodologies developed by researchers into Wikipedia, the collaborative encyclopaedia written by the internet users, and the problems in implementing their methodologies in educational Wikis.

The fact that Wiki servers contain information that can be analysed for research purposes caught the attention of Wikipedia's researchers. Wikipedia is created on the MediaWiki platform. The information from the server is easy to access and can be downloaded as a database. This information enables measurement of the scale of activity and the growth rates of the different Wikipedias around the world [6].

Wikipedia researchers measure many aspects of Wikipedia: the number of terms/articles, the number of words, the links within the terms, the number of edits per term, the number of authors per term etc. [7]. Some of this information is used to measure the collaboration between Wikipedians.

The first indicator for collaboration in Wikipedia is the number of editors (authors) of a specific article (encyclopedic term). If an article was written and edited by more then one editor it may indicate that collaboration has occurred. The number of editors (often called "diversity" or "authorship") is, therefore, a measurement of collaboration.

A comparative research study that analysed the volume of activity in several wikis led to the conclusion that the number of editors is in inverse relation to the number of articles edited; namely, there is small number of terms which are edited by a large number of editors and a large number of terms edited by a small number of editors. The study also found that most of the terms in the Wikipedia were written collaboratively. Only $7.5 \%$ of the terms in the English Wikipedia were written by a single author, $50 \%$ of the terms were written and edited by more than 7 authors, and $5 \%$ were written jointly by more than 50 different authors! [7].

An opposite correlation was found between the number of pages edited by editors and the number of editors, namely, a large number of editors edited a small number of articles and a small number of editors edited a large number of articles. The significance of this finding is that collaboration between editors is not equal. A small group of editors contributes a great deal and the vast majority contributes little.

An important indicator used to measure and analyze collaboration in Wikipedia is the number of edits per 
page. $53 \%$ of the terms in the English Wikipedia were edited 10 times, and only $5 \%$ of the terms were edited more than 100 times. The number of edits per page (called also "rigor") and the number of authors, are claimed to be an indicator of the quality of its content.

The assumption is that a well accepted set of general interest subjects in Wikipedia should be in good standing and reputation, because they have been heavily visited and edited by many different users on the internet. Therefore, the number of edits and number of unique editors for this set of benchmark articles provides a good indicator of the 'high level of quality' within the Wikipedia project [8].

[9] are pointing to the importance of also taking into account the "visibility" of an article in the Wikipedia. An article that is not visited by many people cannot be compared with a well visited article. The "age" of the article should also be considered. A recently published article cannot be compared with an old one.

"The topic-attention quality model" developed by [10] is a tool to measure the quality of an article by calculating the number of authors, the number of edits (versions) and the number of views per article. This research was conducted on the German Wikipedia and its findings indicate that "the number of editors" variable has the most dominant impact on the quality of the article. This outcome supports [11] theory about the wisdom of crowds.

Another interesting piece of research analysing data logs in Wikipedia was aimed at identifying the nature of activity occurring in an article by only looking at quantitative data. [12] presented a tool that can identify and visualize conflict situations and consensus situations by analysing the history of an article. They argue that rapid changes in a version of an article, including repeating revisions, do not indicate collaboration, but the opposite, a conflict. On the other hand, stability in the version of an article may indicate a consensus between the authors.

\section{WIKIPEDIA VS. EDUCATIONAL WIKIS}

Wikipedia is the best-known large scale project using a wiki platform for co-writing purposes, but it is not the only one. Many universities and other educational institutions around the world are using wikis as a platform for collaborative learning [13]. The Open University of Israel (OUI) started to use wikis for collaborative learning in 2006. Until March 2007, 16 courses carried out learning activities using wikis and several models of use were developed [14].

The evaluation of the wiki project demanded the development of a methodology for measurement of collaboration. The methodologies developed for Wikipedia were not satisfactory for the following reasons.

1. Wikipedia is an open project. Every user on the internet is encouraged to contribute to the wiki. The university's wikis are closed; only students of the specific course can work on the wiki. The number of editors in the university's wikis is limited and is different from course to course. If comparative research is to be conducted, it is important to take into account not only the number of editors but the number of potential editors as well.
2. Wikipedia is an open-ended on-going project. The University's wikis are limited and defined in time they are open only while the course is running. The time period in which the contribution to the educational wikis takes place is of significance - if all the activity were concentrated on the last day of the semester, it would not be regarded as collaborative as if it had spanned the whole semester. If the activity were conducted after the time limit it also would not be considered as collaborative, because other participants cannot benefit from the contribution during this time.

3. Wikipedia is a very structured unified project - it is an encyclopaedia, containing encyclopaedic terms as articles. Educational wikis are more diverse. Some of them are structured like the Wikipedia, as glossaries, but some are used in other ways, for example as a small group workspace, where every group can work on its own sets of pages only. In order to be able to compare collaboration levels between the wikis, the number of potential editors per page should be calculated.

4. Contribution to Wikipedia is voluntary. The activities in the university's wiki may be compulsory. In this case, students must participate in the activity in order to pass the course, so the level of participation would be higher, but does this mean collaboration is higher too? The measurements of collaboration and participation should be clearly separated.

\section{CONSIDERATIONS AND PREPARATIONS}

The special characteristics of educational wikis demanded adjustment of the methodology of collaboration measurement, and some decisions had to be taken before designing the measurement tool. Four main questions had to be answered to serve as the basis for the design of the methodological conclusion for measuring collaboration in educational wikis.

5. Should collaboration be measured at whole wiki or at individual page level?

6. Which pages are relevant in the measurement of collaboration, and how can the log be cleaned of nonrelevant data?

7. How should main page and talk pages be treated separately or jointly?

8. How can students' activity be identified and separated from tutors' activity?

\section{A. Wiki level or page level?}

The first question we had to face in developing a methodology for measuring collaboration in wikis was whether the measurement could be done at wiki level - for the wiki as a whole - or whether collaboration should be measured for each wiki page separately. At first we thought that, in order to be able to rank courses according to their collaborative level, we would have to develop a ranking system that can measure collaboration in the wiki as a whole. However, measuring collaboration can only be done at page level. Students can work on the same wiki simultaneously without having any interaction between them, each student working on his own page. The first indication for collaboration is when more than one student 
is working on the same page in the wiki. Measurement of collaboration must therefore start at page level.

\section{B. Clean-up log}

A number of pages generated by the MediaWiki and by the teachers are not candidates for collaboration. Image pages, template pages, instruction pages created by the teachers, and other pages that are generated automatically by the MediaWiki - all these log lines had to be deleted from the log file.

Another kind of clean-up is related to the duration of the activities. The wiki activities were limited to a specific time slot, but the wikis were accessible to the students for a longer period. Contributions made after the activity deadline would have to be erased from the log file and not considered as collaboration.

A different approach was needed when a wiki was used twice, two semesters in a row. In this case the log file had to be split into two, to divide between the two activities within the same wiki.

\section{Main/Talk Pages}

MediaWiki is designed such that every page is related to a talk page. The purpose of the "talk" page is to discuss issues that are edited in the "main" page. The main page and the talk page have the same name. We had to decide whether to treat the main page and the talk page as separate pages or as one page. The decision was made to treat both pages as one, namely, to look at the history of both pages as one log. In this case, changes in the main page version followed by changes in the talk page would be considered as an indication for collaboration, and not as separate work.

\section{Student/ Tutor identification}

The work in the wikis was done by the students as much as by the tutors. It was necessary to mark all tutors' work, and differentiate it from student work, so that tutors' work would not considered as part of the collaboration. The identification of the tutors in the log file enabled us to investigate further issues, such as the ability to measure the impact of tutors' activities on the volume of students' activities.

\section{How to Measure Collaboration in EdUCATIONAL WIKIS?}

In preliminary research conducted on one course, we defined collaboration as: "contribution of more then one student to a particular page" [15]. This definition helped us identify on which pages collaboration had occurred and to investigate the relation between the presence/absence of collaboration and the level of involvement of the tutor on the page.

The disadvantage of this definition is in its binary form. It can indicate if collaboration has occurred but cannot measure its degree. This definition is therefore not useful for ranking pages according to the level of collaboration. In order to measure collaboration, we must count the number of editors per page (diversity) as has been done in Wikipedia research. Nevertheless, we are dealing with courses in which the number of students is different; some of them are large groups and some of them are divided into small groups, so the number of editors per page cannot in itself be an indicator. It must be measured in relation to the number of potential editors.
The first measurement for collaboration was therefore called "Relative diversity" and was calculated by the formula:

\section{Relative Diversity = Diversity / No. of potential editors}

The value of relative diversity is on a scale between 0 and 1. If a group of five students is able to work on a page but only four students are active and contributing, the level of collaboration would be 0.8 , and if a group of 10 students is able to participate in a wiki activity, but only 6 are active, the level of collaboration would be 0.6 . In cases where only one student edited a page or the page was not edited by any student, the formula would yield a value of zero.

The relative diversity measurement ignores one important matter. The number of editors of a page cannot be the only parameter for measurement in cases of educational wikis. Students who are obliged to participate in learning activities will participate, but on a very small scale and without collaboration. For example, a group of three students are asked to work collaboratively on a page. Each student adds one paragraph to the page. The level of relative diversity will be $100 \%$. On the other hand, another group of three out of three are working very intensively on a page; they are adding, formatting, improving each other's work. In this case, the level of relative diversity will show the same outcome, although it is clear that the second group worked in a more collaborative way.

The example above indicates that collaboration should not be measured only in relation to the number of editors or even the relative number of editors, but also in relation to the number of edits and return edits carried out by the editors. In order to measure the amount of collaboration, it is useful to measure the level of interactivity among the editors. Interactivity has been defined by [16] as:

an expression of the extent that in a given series of communication exchanges, any third (or later) transmission (or message) is related to the degree to which previous exchanges referred to even earlier transmissions [16].

This definition relates to interactivity as a process, and as such, its degree can be measured quantitatively, by the number of interactions among the participants [17].

In the wiki case, the number of interactions cannot be measured as in a forum by the number of messages, but by the number of edits on the "Article" or on the "Talk page". If three students had edited a wiki page or a related talk page only once, and didn't come back to revise or improve the work of their peers, their collaboration would not be considered as intensive as in the case of students who revised their work over and over again.

The formula for calculating intensity will be:

\section{Intensity= Interactivity / Diversity}

The formula for measuring Intensity (Relative Interactivity) on a page of collaboration will start to count the students' edits only from the second time the student was active on a page (return revisions), and will not count consecutive edits by the same student. This number would be divided by the number of students who edit this page (diversity). In this way, the intensity of collaboration among the editors will be measured and can serve as a comparison tool between pages. 
TABLE I.

EXAMPLE

\begin{tabular}{|l|l|l|l|}
\hline & \multicolumn{1}{|c|}{ Page 1 } & \multicolumn{1}{c|}{ Page2 } & \multicolumn{1}{c|}{ Page 3 } \\
\hline & $\begin{array}{l}\text { Edit_tutor } \\
\text { Edit_stud 1 } \\
\text { Edit_tutor } \\
\text { Edit_stud 1 } \\
\text { Edit_tutor } \\
\text { Edit_stud 1 } \\
\text { Edit_stud 1 }\end{array}$ & $\begin{array}{l}\text { Edit_stud 1 } \\
\text { Edit_stud 2 } \\
\text { Edit_stud 2 } \\
\text { Edit_tutor } \\
\text { Edit_stud 1 } \\
\text { Edit_tutor }\end{array}$ & $\begin{array}{l}\text { Edit_stud 1 } \\
\text { Edit_stud 2 } \\
\text { Edit_stud 3 } \\
\text { Edit_stud 2 } \\
\text { Edit_stud 2 } \\
\text { Edit_stud 4 } \\
\text { Edit_stud 3 }\end{array}$ \\
\hline $\begin{array}{l}\text { Number of potential } \\
\text { students }\end{array}$ & 4 & 4 & 4 \\
\hline $\begin{array}{l}\text { Diversity: Number } \\
\text { of active students }\end{array}$ & 1 & 2 & 4 \\
\hline Relative Diversity & 0 & 0.5 & 1 \\
\hline $\begin{array}{l}\text { Interactivity } \\
\text { Number of returns }\end{array}$ & 0 & 3 & 2 \\
\hline $\begin{array}{l}\text { Intensity of } \\
\text { collaboration }\end{array}$ & 0 & 1.5 & 0.50 \\
\hline
\end{tabular}

This table describes three cases of three different pages and the results of the measurements described above.

In the first case (page 1), the number of potential students who could work on the page was 4 but only 1 student (Edit_stud 1), and the tutor (Edit_tutor) were active.

In the second case (page 2), the number of potential students who could work on the page was 4 but only 2 students and the tutor were active.

In the third case (page 3), the number of potential students who could work on the page was 4 and all of them were active.

Therefore, in terms of "Diversity" and "Relative Diversity", the "page 3" group was more collaborative. In terms of "Intensity" the "Page 2" group was more collaborative because the interactions between the students were more intensive. "Page 1" was not collaborative at all $(0)$ due to the fact that only one student contributed to the page.

\section{CONCLUSIONS}

Measuring collaboration in educational wikis is different from measuring collaboration in public open wikis like Wikipedia. Measuring collaboration by counting the number of editors per page is not enough in the educational setting. It could indicate the degree of participation in the assignment but would not reflect the intensity of collaboration among the group members.

In order to be more accurate in the measurement of collaboration of the group work, and in order to be able to compare groups and to rank them by the intensity of collaboration they have produced, it is better to measure the degree of intensity of collaboration among the members alongside the number of editors per page.

\section{ACKNOWLEDGEMENT}

We would like to thank MEITAL (The Israeli InterUniversity Centre for E-Learning - IUCEL) for funding this research.

\section{REFERENCES}

[1] Swan, K. Shen, J. \& Hiltz, R. 2006. Assessment and collaboration in online learning. Journal of Asynchronous Learning Networks, $10(1), 45-62$.
[2] MacDonald J. (2003) Assessing online collaborative learning: process and product, Computers \& Education, Vol. 40, Issue 4, PP. 337-391

[3] Aguar N. Reitman, R. \& Zhou, W. 2004. Teaching and learning online with wikis, Proceedings of the 21st ASCILITE Conference.

[4] Bruns, A. and Humphreys, S. 2005. Wikis in Teaching and Assessment: The M/Cyclopedia Project, Retrieved November, 8, 2005:

http://snurb.info/files/Wikis\%20in\%20Teaching\%20and\%20Asses sment.pdf.

[5] Forte, Andrea and Amy Bruckman. 2006. From Wikipedia to the Classroom: Exploring Online Publication and Learning. Proceedings of the International Conference of the Learning Sciences, Vol 1. Bloomington, IN, 182-188.

[6] Voss J. 2005. Measuring Wikipedia, In Proceedings International Conference of the International Society for Scientometrics and Informetrics ISSI : 10th, Stockholm (Sweden July 24-28, 2005). Online: http://eprints.rclis.org/archive/00003610/.

[7] Luciana B., Carlos C., Debora D., Stefano L. and Stefano M. 2006. "Temporal Evolution of the Wikigraph". In Proceedings of the Web Intelligence Conference, pp. 45-51. Hong Kong, December 2006. IEEE CS Press.

[8] Lih, A. 2004. Wikipedia as Participatory Journalism: Reliable Sources, Matrix for Evaluating Collaborative Media as a News Resource. In Proceedings of the 5th International Symposium on Online Journalism (University of Texas at Austin, April 16-17, 2004) Online: http://jmsc.hku.hk/faculty/alih/publications/utaus tin-2004-wikipedia-rc2.pdf (last retrieval April 01, 2006).

[9] Wilkinson D. M. \& Huberman B.A. 2007. Assessing the Value of Cooperation in Wikipedia, Digital Libraries (cs.DL); Computers and Society (cs.CY); Physics and Society (physics.soc-ph) http://arxiv.org/abs/cs.DL/0702140v1.

[10] Brändle A, 2005. Too Many Cooks Don't Spoil the Broth, In Proceedings of the Wikimania'05 (Frankfurt am Main, Germany, August 4-7, 2005).

[11] Surowiecki J. (2004), The Wisdom of Crowds. New York: Doubleday.

[12] Viegas Fernanda B. Wattenberg M., Dave K. 2004. Studying cooperation and conflict between authors with history flow visualizations, In Proceedings of the SIGCHI conference on Human factors in computing systems (CHI'04) Vienna, Austria, pp: $575-582,2004$

[13] Parker, K.R. and Chao 2007. J.T Wiki as a teaching tool, Interdisciplinary Journal of Knowledge and Learning Objects, 3: 2007.

[14] Tal - Elhasid, E. \& Meishar-Tal, H. 2007. Models for Activities, collaboration and assessment in wiki in academic courses, Proceeding of EDEN 2007, (June 2007, Napoli, Italy).

[15] Tal-Elhasid, E. \& Meishar-Tal H. 2006. Wiki as an Online Collaborative Learning Environment at the Open University, Mashabei Enosh (Human Resources), 6-225, 48-53 (Hebrew)

[16] Rafaeli, S. 1988. Interactivity: From new media to communication, In Sage Annual Review of Communication Research: Advancing Communication Science, Vol. 16, eds R. P. Hawkins, J. M. Wiemann and S. Pingree, 110-134. Beverly Hills, CA: Sage.

[17] Rafaeli, S., \& Ariel, Y. 2007." Assessing Interactivity in Computer-Mediated Research". In: A.N Joinson, K.Y.A McKenna., T. Postmes \& U-D. Reips (Eds). The Oxford Handbook of Internet Psychology. Oxford University Press.

[18] Angelo (1999) Doing assessment as if learning matters most, AAHE Bulletin, 1999.

\section{AUTHORS}

Hagit Meishar-Tal and Edna Tal-Elhasid are with the Shoham Centre, The Open University of Raanana, Israel.

This article was modified from a presentation at the International Conference of Interactive Computer Aided Learning ICL2008, September 24 - 26, 2008 in Villach, Austria. Manuscript received 2 December 2008. Published as submitted by the authors. 